\title{
Media Literacy in the Time of Covid
}

\author{
Julian McDougall and Karen Fowler-Watt, \\ Centre for Excellence in Media Practice, Bournemouth University, UK \\ Lee Edwards, London School of Economics, UK
}

\begin{abstract}
In the early stages of the pandemic, U.N. Secretary-General Antonio Guterres warned that the world was not only fighting coronavirus "but our enemy is also the growing surge of misinformation". (Associated Press, 28.3.20).

Media literacy in the time of Covid is situated at an intersection between its value as an educational innoculation against misinformation in general and the urgency of a rapid response to misinformation about the virus. Media literacy in this context takes on a role in public health.

This article reviews the evidence for the effectiveness of media literacy in both contexts, collating findings from reviews conducted for the UK Department for Culture, Media and Sport (DCMS), European Commisssion, US Embassy and UK Office of Communications (OFCOM), together with a rapid evidence analysis of media literacy with an applied, specific focus on 'Covid fake news'.
\end{abstract}

KEYWORDS: Media Literacy, Misinformation, Covid-19, Public Health. 


\section{The Intersection: Media Literacy, Misinformation \& Covid-19}

As the coronavirus crisis has developed, conspiracy theories and health misinformation, often circulating on social media, have brought the importance of media literacy - the ability to identify, understand and critically evaluate different types of media - to the forefront of public discourse. Whilst the international media literacy community of practice has much to offer in this space, it is also wary of short-term, reactive solutionism, as the evidence demonstrates the importance of critical media literacy being developed over time, as a sustainable mindset for both resilience to misinformation and critical awareness of the representational dynamics of all media.

The Reuters Institute for the Study of Journalism, in June 2020, reported their findings that public trust in both news media reporting and government briefings about the pandemic were in decline. In the two months previous, the Institute surveyed news and information access about the virus in six countries and found a rise in news consumption and a trust gap between information from news organizations and social media and video sites, whilst the circulation of fake news about the role of 5G technology in the spread of the virus was the subject of both media and academic interest. Later in 2020, the International Center for Journalists (ICFJ) and Tow Center at Columbia University conducted a survey of 1400 Englishspeaking journalists worldwide and reported just under half of respondents citing politicians and elected officials as frequent sources of disinformation. Eighteen months into the pandemic, Steensen (2021) reported interim findings on 'News from the Desert', an actor-network and auto-ethnographic study of how Covid disinformation has thrived in communities left behind by journalism. These included opportunities for 'unexpected actors' to take charge of local public discourse in the absence of trust in regional journalism, for example Facebook group administrators. This emergence, combined with the lack of recognizable editing processes, has enabled misinformation about the virus to thrive, a phenomenon that the World Health Organisation (WHO) describes as an 'infodemic', a situation where there is:

too much information including false or misleading information in digital and physical environments during a disease outbreak. It causes confusion and risk-taking behaviours that can harm health. It also leads to mistrust in health authorities and undermines the public health response

The potential for media literacy to offer a response to misinformation (false, inaccurate or misleading information), had been established by Hobbs (2017), who provided applied research into teaching responsiveness to conspiracy theories, informed by an understanding that the impact of exposure to conspiracy thinking is a highly significant aspect of information disorder. In our previous work, we reviewed the international field of media literacy and Media Studies to assess its capacity to oppose fake news (see Fowler-Watt and McDougall, 2019, McDougall, 2019). This range of work has now been applied with renewed urgency to Covid conspiracies. During the first year of the pandemic, rapid responses to the global public health emergency were using research published before the pandemic to help make sense of Covid misinformation and new studies were being commissioned which were directly investigating media literacy in times of Covid alongside industry initiatives seeking to restore trust and engage marginalized communities (for example, the BBCs Media Action charitable project).

In this article, we collate reviews, which the authors conducted, of the evidence of impactful research addressing the efficacy of media literacy for resilience to misinformation more broadly. We analyse the applicability of this pre-pandemic work to Covid health information and provide evidence emerging from new media literacy research undertaken during the crisis and specifically focused on media literacy in the context of Covid, in order to assess the value of media literacy at the intersection of misinformation and public health challenges.

\section{Scope and Methods}


For the European Commission review (McDougall et al, 2018), secondary data was derived from peer reviewed academic literature, international policy reports, verified comparative studies, and disseminated research projects with proof of concept or evidence of impact. Systematic searches were conducted for peer-reviewed articles published since 2010 in EBSCO Educational Databases including the Education Resources Information Center (ERIC) and the Teacher Reference Center (TRC), using the search terms 'media education', 'media literacy', 'digital literacy', 'media studies' combined with, 'secondary education', 'teaching practices', 'disinformation', 'misinformation”, and 'fake news'. After screening, 38 publications from Europe and 107 publications from non-European countries were selected and analysed according to the study's conceptual framework and research questions. This review was then triangulated with European network and action reports; international conference abstracts and proceedings and materials and research produced by European and international government departments and agencies, international organisations or non-governmental organisations ('grey literature'). Structured searches of recent empirical evidence, pedagogic resources and European funded project outcomes in the public domain were conducted and 'snowball' methods were used to gather additional research data.

The US Embassy-funded research (McDougall, 2019; Fowler-Watt and McDougall, 2019; CEMP, 2019) consisted of ethnographic research combining a field review, 25 interviews with media educators and journalists and four multi-stakeholder workshops, bringing together and capturing dialogue between media educators, journalists, students and information professionals. The interviews were transcribed and analysed for key discursive patterns. Participative workshops to explore experiences of 'fake news', questions of trust and perceptions of media literacy as a response, were held at the Media Education Summit in Hong Kong, the English and Media Centre in London, the National Higher Research University in Moscow and Loughborough University's campus at Olympic Park, London. The total number of participants, including the interviewees and participants in the workshops, was 88 . The field review for this project was a narrative review, collated by the research team and evaluated with the stakeholders, but not subject to systematic scoping or parameters.

The mapping exercise commissioned by the Department for Culture, Media and Sport (RSM / CEMP, 2020) provided a review of online media literacy initiatives for UK users to feed into the Government's Online Harms White Paper towards the development of a media literacy strategy for online safety. The review consisted of a mapping exercise of digital media literacy initiatives and a literature review of media literacy acquisition and barriers in the UK. The scoping parameters employed included target user group; provider type; scale, reach and longevity; focus of approach; delivery method and the sub-sets of media literacy skills and capabilities involved.

The Ofcom research (Edwards et al, 2021) was a rapid evidence assessment of research focused on the intersection between online misinformation and media literacy. In the first stage of the research, scoping grey literature and conducting expert interviews identified existing media literacy practices designed to address misinformation, initiatives in fields outside media literacy to tackle misinformation, current trends in misinformation production and circulation, and technological interventions by platform operators to address misinformation. In the second phase, the main review and meta-analysis was conducted, drawing on search terms and findings identified in stage one. Searches were conducted on 16 multidisciplinary and subject-specific databases were scanned, producing 1,767 unique results. Screening generated a final sample of 201 articles for review, grouped according to four themes: media literacy interventions addressing misinformation; technical interventions addressing misinformation; media literacy practices and audience responses to interventions.

For this article, we first review the findings of these four broader projects that speak directly to media literacy as a response to, or for preventative resilience-building for misinformation in general. We then present the rapid review of evidence for media literacy as a specific intervention with regard to the problem of Covid-19 misinformation, conducted for this article as a narrative review of published evidence in the public domain, peer reviewed and published and / or disseminated and curated through recognized, international media literacy and media education networks and events. The findings from the first group of studies are then reviewed in light of the results of the additional rapid evidence review. 


\section{Findings: Media Literacy and Misinformation}

In the second part of this article, we review the findings of the three reviews of media literacy for resilience to misinformation in general and generate from those a set of conclusions about the evidence of media literacy as a specific response to covid misinformation.

Wardle and Derakhshan (2017) describe 'information disorder' as a crisis arising from the combination of online misinformation; mainstream media disseminating 'poor quality information' through the web; a weakened local media reducing diversity, narrowing representation and ultimately undermining democracy; the use of data for demographic targeting and the deployment of 'bots' for large-scale viral circulation of misinformation. Their Council of Europe commissioned report identifies three elements the agents that create disinformation; the format of the message and the process of reception and interpretation which leads to people sharing through viral processes. In the UK, the London School of Economics (2019) provides a policy framework for tackling the information crisis focused on ' 3 Ts' trust, truth and technology and, like the Council of Europe, defines the crisis as a new convergence of elements, '5 Evils' consisting of confusion, cynicism, fragmentation, irresponsibility and apathy. UNESCO (2017) defined the required response to information disorder as 'Operation Decontamination', again locating 'fake news' as part of a societal information challenge arising from simultaneous technological, economic and political developments. This contamination occurs when traditional media are undermined, information abundance overrides reliability, fact and opinion are harder to distinguish, public trust reduces.

The European Commission review of effective media literacy practice in secondary schools for responding to information disorder provided a set of key findings. There was clear evidence that the spread of disinformation and 'fake news' was having a negative impact on students and their learning. The consequences of disinformation campaigns have also presented significant challenges to teachers who seek to convey the value of evidence to their students, especially in subject areas that are prone to propaganda such as science, history and citizenship education. Media literacy initiatives were shown to lessen the vulnerability of children to disinformation as the development of critical thinking and analytical competences specifically targeted at media are key components of a successful educational intervention.

There is, however, an ongoing debate on the best strategy to address students' susceptibility to disinformation, revolving around the extent to which interventions should target a person's core belief system and worldview (Lewandowsky et al., 2017, Hyman and Jalbert, 2017). Media literacy campaigns against propaganda and disinformation have historical precedents that can inform present efforts to combat vulnerability to disinformation. At the same time, there are many current educational initiatives that improve students' capacity to detect disinformation and protect themselves against its influence. Evidence shows that students who reported high levels of media literacy learning opportunities were more likely to identify misinformation, which lends credence to the impact of media literacy programmes (see Kahne and Bowyer (2017). Educational programmes across Europe's schools to combat conspiratorial thinking often involved professional journalists helping to teach students how to check the authenticity of information and to understand how advertisers and others use students' personal information to influence them (see Entre les lignes' and Faktana, kiitos!). Successful implementation of media literacy education at the school level was often facilitated by approaches to pedagogy that combined and/or crossed boundaries between spaces and roles - the classroom and the extended 'third space', teachers and students working in partnership to co-create learning, and professional development in hybrid combinations of physical and virtual networks. There was credible, empirical evidence of more formal, funded, partnership engagements between media literacy educators and media industries, literacy organisations, NGOs and other stakeholders at the level of resource production and single events being effective (see Castellinaria' Associazione REC; SUPSI; Televele; MediaWise).

The US Embassy funded ethnography set out from a field review which used a report from the US Data and Society Research Institute as an establishing framework, whereby media literacy needs to "develop a coherent understanding of the media environment, improve cross-disciplinary collaboration, leverage the current media crisis to consolidate stakeholders and develop curricula for addressing action in addition 
to interpretation". (Bulger and Davison, 2018: 4). The project moved on to interviews with media literacy practitioners and multi-stakeholder participant workshops. Whilst the status of 'fake news' is always configured according to the discourse which speaks it, the working definition used for this project was to distinguish it by its explicit and deliberate intention to mislead or distort, often, but not always, political and economic, from 'clickbait' attention generation for advertising and / or the financial trading of data. The review situated fake news as a symptom of something broader, than a media / technological phenomenon, with the economic crash of 2008 providing a significant context, if not a direct cause, of 'post truth'. One important aspect is the evidence that societies lack consensus on the role of journalism and the concept of 'public interest'. In the UK, Media Studies (as a formal subject taught in schools) asks quantitative and environmental questions about who is making use of what media and then qualitative questions about how they interpret media and its function in their lives. Media Studies' focus on media texts and a range of approaches to textual reception which enable the media student to deconstruct the ways in which meaning is made in and between texts can be compared with media literacy initiatives, such as 'extra-curricular' activity in the US (e.g., Mihailidis, 2018) towards a civic, values-oriented media literacy. The US Embassy research arrived at the conclusion that media literacy should resist the idea that the task is to teach students the difference between fake news and 'the real thing'. Instead, critical media literacy will facilitate healthy cynicism about and resilience to all media and media literacy education should seek to enable a porous 'third space' knowledge exchange (using pedagogic 'scaffolding' approaches, from Vygotsky) between academic perspectives on critical thinking about media and students' 'lifeworld' engagements with collective civic media literacies, such as they already exist. From data generated by workshops organized with students, teachers, journalists and information professionals, the research found that stakeholders perceive the problem to be not only about information disorder but also the failure of education to create resilient, critical thinkers. There was also a shared view that the lack of a civil, debating culture in state education is part of the problem. On questions of trust, participants agreed that the 'blind trust' in social media was a problem, that genuinely trustworthy media would have no hidden agenda but that, in the 'post-truth' era, there might be a generational distinction between a broad scepticism and a more trusting engagement. Two themes emerged as points of agreement, a shared scepticism about objectivity in journalism and media representation more broadly and an agreement that media literacy needs to include the critical study of algorithms. On trust, journalists articulated a different discourse, focused on defending the profession. There was also a much clearer sense of definition of terms from journalists than the other groups, distinguishing professional media from 'fake news'. The library professionals were the closest other group to journalists, describing the critical practices needed more in terms of information literacy and checking sources. Students and teachers were generally either more sceptical about the term 'fake news' or less inclined to see a distinction between fake and real. The study drew three key recommendations from working across multiple stakeholder groups to arrive at a consensus point on how media literacy can address 'fake news'. First, rather than producing competence frameworks for media literacy, as though it is a neutral set of skills for citizens, media literacy needs to enable students to apply critical, dynamic approaches to media. Second, media literacy should further enable experiential, reflexive aspects of media practice, with reciprocal transfer between critical rhetoric and creative practice in order to respond academically to media as, primarily, a question of representation. In other words, resilience to representation is enhanced by expertise in representing. Third, media literacy also, and urgently, needs to include the critical exploration of social media, algorithms and big data, accompanied by applied practical learning in the uses of them.

The mapping exercise for the DCMS identified just under 150 media literacy initiatives in the UK. Children were the most common audience, whilst vulnerable groups were the least included, with under $5 \%$ of initiatives intending to reach them. 3\% of activity only intended to support the media literacy needs of people from disadvantaged socio-economic backgrounds. Evidence of the impact of media literacy initiatives was impeded by the lack of a common evaluation framework but generally, initiatives reviewed were categorized with regard to more critical engagement with media, with over half of evidence relating to the ability to recognize misinformation of various kinds and also to be resilient to deceptive use of technology. This critical media engagement was understood to mean the ability to assess media content for truthfulness and reliability, be critically aware of the motivations of content producers and therefore to make more informed decisions about content and selection. More holistic media literacy attributes which we advised for inclusion in the scoping exercise, such as creativity, intercultural dialogue and 
participation and engagement were largely absent from the findings. The most common funding for media literacy resources were internal resources and government funding, followed by private sector companies. The most common providers were charities, media organisations and public sector. Third sector and private sector providers were also represented, but their initiatives were typically addressing the prevention of online harm related to their own commercial practices.

The Ofcom study (Edwards et al, 2021), the most recent of the reviews looking at international media literacy activities pre-pandemic, identified a number of findings about the effectiveness of media literacy as a tool to tackle misinformation specifically. Included in the review were studies that examined the effectiveness of technical interventions, such as platform-initiated fact-checking or flagging of content, which incorporated elements of media literacy such as critical thinking. The review found clear evidence that media literacy interventions, whether integrate into classroom activities, or as part of a technologybased initiatives, do have a positive effect on the ability to critically engage with misinformation. Critical thinking, evaluation strategies and knowledge of the operation of news and media industries are consistently found to improve the ability to deal with misinformation. Pre-existing media literacy facilitates the recognition of fake news and increases the caution with which people approach information on social media, while the ability to critically evaluate source quality is fundamental to both higher levels of media literacy and more cautious attitudes towards misinformation. Moreover, interventions that use 'system 2' thinking, where audiences are required to engage thoughtfully and rationally with content or with misinformation interventions such as warning flags, were consistently found to be more effective than interventions relying on instinctive, rapid engagement with information that requires much less cognitive engagement ('system 1' thinking). Perhaps for this reason, the small number of studies on games and gamification techniques designed to help audiences engage critically with misinformation, all produced positive results, echoing the findings from the European Commission review.

These consistent findings notwithstanding, the review also identified gaps in current research and challenges associated with the implementation and measurement of media literacy as a tool for tackling misinformation. First, evidence of interventions that can produce long-term behaviour change remains rare; most studies adopt an experimental approach, and results are rarely tested in the field, to see whether they hold in the more complex 'real-world' environment. Longitudinal studies are scarce, and where studies do assess the longevity of effects, the results are inconclusive. Most studies are carried out with adult populations, rather than younger students and children, so that the value of media literacy interventions at an early age is still under-researched. Moreover, definitions of media literacy vary across studies, so that accurate comparisons or aggregations of results are difficult. Information and news literacy are more commonly investigated than broad forms of media literacy. Levels of knowledge about the broad production and economic operations of media industries, and the civic dimensions of media literacy (as identified in the US Embassy study), tend to be neglected.

Finally, and as with the US Embassy research findings, the Ofcom review, which was a rapid evidence assessment of research focused on the intersection between online misinformation and media literacy, found that the media literacy curriculum is significantly challenged by changing online landscapes and platforms, including rapidly evolving algorithmic technologies, digital infrastructures and user interfaces. These all affect the interactions audiences have with misinformation, but they are very difficult to keep up with in curricula, and to capture in research. Reflecting this, research tends to focus on only a few digital contexts (mainly Facebook and Twitter), prioritizing text over image, and neglecting newer, very popular platforms and technologies, such as WhatsApp, Instagram, Tumblr, SnapChat or Pinterest.

Our synthesis and analysis of these four reviews into the potential of media literacy education to increase young citizens' resilience to misinformation, in general, combining systematic and narrative approaches, stakeholder consultations and ethnography, presents a framework of five key evidence points to take forward into the review of efficacy for addressing the situation in the context of Covid:

1. There is more evidence of the success of media literacy as a form of critical, reflexive thinking in building resilience to misinformation than of the acquisition of skills and competences; 
2. Pedagogic strategies with evidence of impact include partnerships with nonformal actors and journalists, gamified learning contexts and 'third space' knowledge exchanges between learners' existing knowledge repertoires from their media engagements and the development of critical thinking with media theories and source verification;

3. There is urgent need to extend media literacy to include algorithms; data mining; visual as well as text-based information, and popular platforms other than Facebook and Twitter;

4. Media literacy initiatives are currently skewed towards more easily reached groups and these can exclude marginalized and vulnerable cohorts who may be at greater risk from misinformation;

5. There is also an urgent need for consistent evaluation criteria for how media literacy increases resilience to misinformation.

\section{Findings: Media Literacy, Misinformation \& Covid-19}

In this section, we turn our attention to evidence of the efficacy of media literacy as a response to misinformation specifically about the pandemic. Our methodology for this is a narrative review of peer reviewed work, projects and interventions disseminated across media literacy networks and communities of practice. As such, this data set is less systematic than the reviews into media literacy and misinformation in broader terms, prior to covid.

Since 2020, research that specifically investigates media literacy and Covid-19 misinformation mainly applies existing knowledge about media literacy to the context of pandemic misinformation. A wide range of articles, blog posts and online resources describe and justify the importance of media literacy for resilience to misinformation about the virus but refer back to pre-pandemic media literacy research and / or share findings from surveys into the problem, and cite media literacy as the solution, as opposed to offering evidence from 'Covid times' (see Jolls, 2020; Polizzi, 2020).

UNESCO's Global Alliance for Media Literacy (GAPMIL) offered a prompt response to Covid misinformation, including online resources and webinars, declaring that:

Together, we can help stop the spread of misinformation, control the information fog, and better focus on developing healthy media and information environments for all. We thus shout clarion call of media and information literacy for all (UNESCO, 2020).

Elements of the response were specific and targeted, including youth engagement to address Covid-19 misinformation; online discrimination and information overload during the pandemic; African youth on the frontline of the crisis; tips for parents on dealing with Covid information with children; Philippine youth responses to Covid fake news and "Empathic Communication and Dialogue: Ubuntu, Solidarity and Healing Letters in Pandemic Times". These responses were more in keeping with the body of work which is presenting 'MIL' as an applicable, adaptable resource to a new situation, for example 'as a defence against privacy and data protection infringements'; and 'supporting people with disabilities on the web' and 'MIL Parenting'.

Austin et al (2021), in a kind of hybrid contribution, used a model derived from established media literacy capabilities (from NAMLE, 2017) to test the hypothesis that, as media literacy enables agency in information environments, media literate citizens would be better placed to interpret emerging health information in a time of crisis and develop self-protective behaviours:

The results, verified in two cross-sectional surveys, deployed at two time points with different, nationally representative samples, highlight the important of skills to interpret health and science information in a complex media environment. Individuals with more media literacy are better prepared and willing to take experts' recommended preventive actions. (Austin et al, 2021: 11)

A plethora of studies and resources responded to the media literacy skills needed by children and educational practitioners during lockdowns, in the enforced 'rapid pivot' to remote learning. Whilst these 
are outside of the scope of this review, one related sub-strand of this work responds to the issue of verification of sources in the rush to embrace open access e-learning, the socio-political provenance of ed-tech providers and ways in which the use of social media by schools during lockdowns may have unintentionally increased exposure of younger students to Covid-19 misinformation, for example in the Gaza Strip (Radwan, Radwan and Radwan, 2020).

Another study investigated intersectional disadvantage among BAME communities at greater health risk from the virus but, potentially, also at greater risk from misinformation. Austin, Borah and Domgaard (2021), following the identification of Covid disinformation themes targeting Black communities, researched the efficacy of media literacy for resilience to such profiled health disinformation.

A combination of general and science-specific measures for media literacy, political engagement, and the specific situation of the COVID-19 crisis provided an opportunity to examine relationships between media literacy and the effects of COVID-19 disinformation campaigns. (Austin, Borah and Domgaard, 2021: 8)

Therefore, whilst this study generates important new knowledge at this intersection, like many of the studies in current circulation, the findings are at the level of assessing the media literacy skills of participants, diagnosing (from examination) the problem of Covid misinformation targeting vulnerable communities and then prescribing media literacy as the remedy, as opposed to providing empirical evidence of its efficacy.

Ashrafi-rizi and Kazempour (2020) offer a typology of Covid-19 (mis)information which moves onto a recommendation for media literacy as preventative for people to discern information and develop appropriate behaviours when future crises emerge. Again, an existing conceptual framework for media literacy form is used for the categorization of information, and subsequent challenges for communities, and the development of media literacy, through education, is presented as important in the future, but the study does not directly address media literacy during this pandemic. Johara, Taher and Uddin (2021) applied random sampling to analyse data from their faculty members to evaluate their resilience to misinformation and their relative degrees of media literacy, addressing also the complexity of how social media moderating behaviours relate to the capability to recover from adversity and knowledge of awareness of events in the immediate environment related to the virus.

The above are examples of studies conducted during the pandemic which diagnose misinformation challenges with regard to public health and situate media literacy as either solution or prevention, as either an aspect of or pre-requisite for health literacy. One more forward-looking example is from Vraga, Tully and Bode (2020). This study also presents the existing knowledge on media literacy as a prospective tool for social media users, in particular, to deploy for responding to Covid misinformation:

In many ways, Covid-19 represents a novel pandemic, in terms of its spread and impact on the global economy as well as the media environment in which people learn about the virus and its effects. But we can build from existing research to improve how we respond to misinformation about the virus. Fostering news and science literacy provides a flexible solution that can help people distinguish quality information about Covid-19 and empower more active curation of their social media feeds to protect themselves and others from misinformation. (2020: 477).

However, it differs from others cited here in its call for research in Global South contexts, rather than a 'universal' methodology with the attendant risks of colonial epistemologies. Another distinctive contribution in this space comes from Gerosa, Gui, Hargittai and Nguyen (2021) who offered a forensic analysis of American citizens' susceptibility to Covid-19 misinformation in correlation to their educational qualifications, as opposed to extracting media literacy as a discrete attribute in the 'knowledge-gap hypothesis' (and the implications of such for public health messaging): 
Our findings suggest that those with a lower education level are at a structural disadvantage when it comes to learning about guidelines to limit the spread of COVID-19 and protecting themselves and others. If the media do not differentially contribute to knowledge acquisition for people with varying education levels, then knowledge gaps are mostly based on previous knowledge or on the ability to interpret new information through the lens of existing information literacy. (2021: 16)

The importance of these empirical findings is clear to the media literacy field. It will be essential in the next phase of research into media literacy and resilience to Covid-19 misinformation to be able to compare media literacy as the outcome of specific education (whether sustained, such as Media Studies in the UK, or the focus of small-scale projects or interventions, in the broader field of media literacy) with media literacy as inextricably linked to, or a 'by-product' of higher levels of education in general terms, and the critical thinking that is developed therein.

At the Media Education Summit in 2021, an international conference convened during the second year of the pandemic, drawing a community of media literacy researchers and practitioners to share research, several studies relating to media literacy in the time of Covid were disseminated, but these were all focused on media education pedagogies for remote or virtual learning (Das, 2021; Holt, 2021; Rukmi, 2021; Scott, 2021). Similarly, the Media Education Lab's 2020 forum, 'Crisis Creates Opportunity' explored how the pandemic had advanced digital media literacy in US schools by enabling students to share their lived experiences of isolation through digital media and teachers to model new practices in informal peer learning. In addition to MES, the North American Media Literacy Education conference in 2020 and the Salzburg Global Forum on Media Literacy explored the intersection of media literacy, Covid and social justice, specifically around protest and the Black Lives Matter movement, and how inequalities relating to the pandemic were drawn on similar lines, with media literacy for social justice speaking to this intersection. Notable examples from within this strand of current research include Peters-Lazaro and Shresthova's work on civic imagination for 'practising futures' (2020) and Pablo Martinez-Zarate's practice research Forensic Landscapes (2021), a film which offers a vision of immersive media literacy, in which shared experience is understood as 'truth' and thus an antidote to the polarisation of discourse during pandemic. This work locates media literacy during and after the pandemic as being about citizens interacting differently with media ecosystems, as opposed to a set of competences to be measured as more or less developed and assumed to develop resilience.

The European Union Funded Smart-EU project offers a 'Social Media Resilience Toolkit' produced during the pandemic. At this time of this review, three items featured in the toolkit related to media literacy and Covid misinformation, specifically. A partnership between Thomson Reuters and NAMLE provides a podcast, video, classroom discussion guide and infographic on identifying covid misinformation and applying media literacy strategies in response. An online article from Now Toronto curates a series of fact checking and media literacy workshops and resources to tackle 'infotagion' and Knight Center's free MOOC on Disinformation \& Fact-Checking in Times of COVID-19 in Latin America and the Caribbean is publicised. These initiatives are all more focussed on the specific application of media literacy for misinformation resilience in Covid times, but it is too early to evaluate their impacts (see Smart-EU, 2021).

Whilst not included in the scope of this review, a range of digital health solutions to the restrictions imposed on medical services during the Covid crisis included the terms media literacy or digital literacy with regard to the needs of 'e-health' users, and in some cases, these also included the ability to discern health information from misinformation (see, for example Perez-Sust et al, 2020). Kim and Walker (2020) report on a Twitter intervention which "leverages the nature of social media, network structure, and the efforts of volunteer fact checkers." (2020:2).

There have also been research findings shared and projects funded and in progress during this period which offer more specific contexts for how media literacy relates to the capacity to interpret health (mis)information during the crisis. Feigenbaum et al (2021) are investigating the visual representation of 
Covid information in web-based comics across social media platforms. Both the media literacy practices at work in the visual representation of public health messages and the reception of them by readers are addressed. Tilton (2020) reflects on journalists' media literacies when reporting on Covid with the safeguarding of children in mind. A range of studies are investigating children's (virtual) play and development during the pandemic, most notably the Play Observatory (Potter et al, 2020) which does not explicitly focus on children's media literacies with regard to resilience to health (mis) information but does explore the importance of the intersection of play, media and creative expression for wellbeing during the crisis. Like the Feigenbaum study which works at the interdisciplinary convergence of media literacy, data mapping and health information, Potter's project connects media literacy to the study of folklore. These examples indicate a more 'dynamic' development of media literacy methodologies in response to and informed by the pandemic. Musi and Carmi (2020) are developing a 'crisis informatics' approach to global digital activism in times of Covid. Being Alone Together: Developing Fake News Immunity. The methods at work in this study intend to 'reverse-engineer' Covid misinformation, similar to 'mining back' in Feigenbaum's contribution. This sub-field of media literacy research is in the process of using the urgency of the Covid misinformation crisis to move the field on methodologically, but the more empirical findings and sustainable impacts of these studies will be reported and evaluated in the coming years.

\section{Discussion}

In this final section, we bring together our 'review of reviews', the more systematic scoping of prepandemic media literacy for misinformation resilience and our narrative analysis of activity in the time of covid, to draw out two opportunities for the field going forward and two key challenges.

In the early stages of the pandemic, U.N. Secretary-General Antonio Guterres warned that the world was not only fighting coronavirus "but our enemy is also the growing surge of misinformation". (Associated Press, 28.3.20). Media literacy in the time of Covid is situated at an intersection between its value as an educational innoculation against misinformation in general and the urgency of a rapid response to misinformation about the virus.

Our collation of reviews into media literacy for (mis)information resilience in general foregrounded the importance of media literacy as a form of critical, reflexive thinking, an aspect of a broader set of capabilities linking the reduction of risk from 'information disorder' to the capacity to act in creative and civic domains. From the emergent findings of studies investigating media literacy for resilience to Covid misinformation, specifically, it is unclear whether the 'knowledge gap hypothesis' is specific to media literacy or whether media literacy is a by-product of critical thinking associated with higher levels of education. The situation is so complicated and elements so intertwined that it is unclear at this point whether the advantages that more media literate young people have in accessing and engaging with 
remote learning during lockdowns caused by the virus has a subsequent relation with their resilience to misinformation about the virus.

The 'in progress' new sub-field of media literacy research appears to be presenting two opportunities, but also some challenges.

1. The need for an intersectional approach to media literacy and misinformation, which can account for how marginalised groups are more vulnerable to 'Covid fake news' and also left out of the frames of reference for the majority of media literacy initiatives;

2. The growing 'cluster' of media literacy intervention methods which draw on data mining; digital activism; practice research and more dynamic, living literacy practices for a broader objective for wellbeing during the crisis and cohesive community preparedness for future emergencies.

The existing, enduring and no doubt future challenges relate to

A) Developing consensus around the success criteria for this complex range of media literacy work in relation to resilience and reduced vulnerability and

B) Working to apply such criteria in ways that are sufficiently nuanced and situated to account for local and intersectional experiences.

\section{References}

Ashrafi-rizi, H and Kazempour, Z. (2020) 'Information Typology in Coronavirus (COVID-19) Crisis; a Commentary.' Archives of Academic Emergency Medicine 8 (1) e19.

Austin, E. W., Borah, P., \& Domgaard, S. (2021). COVID-19 disinformation and political engagement among communities of color: The role of media literacy. Harvard Kennedy School (HKS) Misinformation Review, 1(7).

Austin, E; Austin, B; Willoughby, J; Amram, O \& Domgaard, S. (2021): 'How Media Literacy and Science Media Literacy Predicted the Adoption of Protective Behaviors Amidst the COVID-19 Pandemic', Journal of Health Communication, DOI: 10.1080/10810730.2021.1899345

Bulger, M. \& Davison, P. (2018). 'The Promises, Challenges, and Futures of Media Literacy. Data \& Society Research Institute': https://datasociety.net/output/the-promises-challenges-and-futures-ofmedia-literacy/.

Centre for Excellence in Media Practice (CEMP) (2019) Media Literacy vs Fake News: Critical Thinking, Resilience and Civic Engagement: http://mlfn.cemp.ac.uk/

Das, M. (2021). 'Bharat Padhe Online- A case study analysis of online pedagogy during pandemic in India.' Media Education Summit, Leeds: 1.4.21.

Feigenbaum, A (2021) Comics in the Time of Covid-19: https://www.covidcomics.org/ahrc-project/

Fowler-Watt, K and McDougall, J. (2019) 'Media literacy versus fake news: fact checking and verification in the era of fake news and post-truth.' Journalism Education 8(1): 60-69. 
Gerosa, T., Gui, M., Hargittai, E., \& Nguyen, M.H. (2021) (Mis)informed during COVID-19: How Education Level and Information Sources Contribute to Knowledge Gaps. International Journal of Communication.

Hobbs, R. (2017). 'Teach the Conspiracies'. Knowledge Quest, 46(1), 16-24.

Holt, J. (2021). 'Audiovisual criticality: video essay as a tool to address diverse educational needs of filmmaking students.’ Media Education Summit, Leeds: 1.4.21.

Jolls, 2020; Media Literacy in the Time of Covid-19. Family Online Safety Institute, 25.8.20: https://www.fosi.org/good-digital-parenting/media-literacy-time-covid-19

Kahne, J., \& Bowyer, B. (2017). 'Educating for Democracy in a Partisan Age: Confronting the Challenges of Motivated Reasoning and Misinformation'. American Educational Research Journal, 54(1), 3-34.

Edwards, Lee; Stoilova, M; Anstead, N; Fry, A; El-Halaby, G; Smith, M. (2021) Rapid Evidence Assessment on Online Misinformation and Media Literacy: Analysis Produced for Ofcom. London: London School of Economics.

Johara, F; Taher, A and Uddin, A. (2021) 'Social Media Literacy and COVID-19 Awareness for Faculty Resilience in a Moderated Mechanism: An Empirical Study'. Bari, M and Alaverdov, E (Eds). Impact of Infodemic on Organizational Performance. Hershey, PA: IGI Global.

Kim, H., \& Walker, D. (2020). 'Leveraging volunteer fact checking to identify misinformation about COVID-19 in social media.' The Harvard Kennedy School (HKS) Misinformation Review, Volume 1, Special Issue on COVID-19 and Misinformation.

Lazaro and Shresthova Practicing Futures: A Civic Imagination Action Handbook

Lewandowsky, S., Ecker, U. and Cook, J. (2017). 'Beyond Misinformation: Understanding and Coping with the "Post-Truth" Era'. Journal of Applied Research in Memory and Cognition, 6, 353369.

London School of Economics. (2019) Trust, Truth and Technology. London; LSE Publications.

Martinez-Zarate, P. (2021) Forensic Landscapes: https://www.forensiclandscapes.com/

Mihailidis, P. (2018). 'Civic media literacies: re-Imagining engagement for civic intentionality'. Learning, Media and Technology. https://doi.org/10.1080/17439884.2018.1428623.

National Association for Media Literacy Education (NAMLE) (2007). Core Principles of Media Literacy

Education in the United States. Available at: https://namle.net/publications/core-principles/.

McDougall, J., Zezulkova, M., van Driel, B., Sternadel, D. (2018), 'Teaching media literacy in Europe: evidence of effective school practices in primary and secondary education', NESET II report. Luxembourg: Publications Office of the European Union.

McDougall, J (2019) Fake News vs Media Studies: Travels in a False Binary. London: Palgrave.

Musi, E and Carmi, E. (2020) 'Being Alone Together': Developing Fake News Immunity:

https://fakenewsimmunity.liverpool.ac.uk/ 
Pérez Sust P, Solans O, Fajardo JC, Medina Peralta M, Rodenas P, Gabaldà J, Garcia Eroles L, Comella A, Velasco Muñoz C, Sallent Ribes J, Roma Monfa R, Piera-Jimenez J. 'Turning the Crisis Into an Opportunity: Digital Health Strategies Deployed During the COVID-19 Outbreak.' Public Health and Surveillance 6(2): e19106 doi: 10.2196/19106

Polizzi, G. (2020) Fake News, Covid-19 and Digital Literacy: Do what the experts do. London: London School of Economics, 17.6.20: https://blogs.lse.ac.uk/medialse/2020/06/17/fake-news-covid-19-anddigital-literacy-do-what-the-experts-do/

Posetti, J; Bell, E and Brown, P. (2020) Journalism and the Pandemic: A Global Snapshot of Impacts. International Center for Journalists: https://www.icfj.org/sites/default/files/202010/Journalism\%20and\%20the\%20Pandemic\%20Project\%20Report\%201\%202020 FINAL.pdf

Potter, J; Cowan, K; Olusaga, Y; Cannon, M; Bishop, J; Bannister, C and Signorelli, V. (2020) Play Observatory: https://play-observatory.com/

Radwan, Q; Radwan, A \& Radwan, W. (2020). 'The role of social media in spreading panic among primary and secondary school students during the COVID-19 pandemic: An online questionnaire study from the Gaza Strip, Palestine.' Heliyon, Volume 6, Issue 12, https://doi.org/10.1016/j.heliyon.2020.e05807.

RSM / CEMP (2020). DCMS Online Safety - Media Literacy Strategy. London: RSM Consulting.

Rukmi, N. (2021). 'Students' Perceptions towards Distance Learning with Online Collaborative Platforms: A Case Study.' Media Education Summit, Leeds: 1.4.21.

Scott, D. (2021). 'Following Formats: Body Language in the Future of Diversified E-Learning Environments.' Media Education Summit, Leeds: 1.4.21.

Smart-EU. (2021) Social Media Resilience Toolkit: http://smart-toolkit.eu/

Steensen, S. (2021) Dealing with Covid in news deserts: How pandemic-related news and (mis)information flow in local communities left behind by journalism. Presentation to the Science, Health and Data Communications Research Group, Bournemouth University, 26.5.21.

Tilton, S. (2021) 'There is a difference between being aware and being afraid: journalistic media literacy during the era of COVID-19.', Journal of Children and Media, 15:1, 69-

72, DOI: $\underline{10.1080 / 17482798.2020 .1859395}$

UNESCO (2017) The Unesco Courier: The Media: Operation Decontamination. https://www.unesco.at/fileadmin/Redaktion/Publikationen/UNESCOCourier/UNESCO_Courier_2_2017.pdf

UNESCO (2020) UNESCO MIL Alliance response to COVID-19: https://en.unesco.org/themes/mediaand-information-literacy/gapmil/covid19

Vraga, E; Tully, M and Bode, L. (2020) 'Empowering Users to Respond to Misinfromation about Covid-19.' Media and Communication 8 (2): 475-479.

Wardle, C. and Derakhshan, H. (2017) Information Disorder Toward an interdisciplinary framework for research and policymaking. Strasbourg: Council of Europe.

NGOs referenced 
www.castellinaria.ch.

www.t-rec.ch.

http://televele.hu/english/

http://mediawise.ro/about-us/what-we-do-educatie-media/ 